\title{
EDITORIAL
}

\section{Mortality in COPD patients with community-acquired pneumonia: who is the third partner?}

\author{
A. Torres* and R. Menéndez ${ }^{\#}$
}

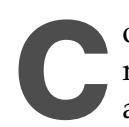
ommunity-acquired pneumonia (CAP) is one of the most frequent medical causes of hospital admission and still carries a high morbidity and mortality. Recent data from the European Respiratory Society [1] have estimated that the cost of the in-patient care for CAP in Europe is $€ 5.7$ billion. The mortality of hospitalised patients with CAP is still very high, ranging 5-15\%, despite the availability of good and potent antibiotics and very effective supportive measures. In order to adequately fight against the mortality of CAP, it is important to know the factors associated with death. Several studies have addressed this issue and we now have in our hands scores that predict mortality very well and are, in fact, used to select patients with a higher or lower probability of death $[2,3]$. By contrast, there is not much information about interventions or host particularities that may be protective against death or complications. Importantly, interventions related to better outcome [4] are adequate and is early antibiotic therapy [5], as well as adherence to CAP guidelines. In a recent study on a large series of nonresponding CAP patients, MENÉNDEZ et al. [6] found that influenza vaccination, the administration of antibiotics and chronic obstructive pulmonary disease (COPD) were protective factors for nonresponse to initial antibiotics. The finding that COPD was protective for nonresponse was very intriguing and difficult to interpret.

COPD and chronic bronchitis are the most frequent comorbidities in hospitalised patients with CAP, ranging 25-50\% [7]. Some studies have provided information about COPD patients with CAP. A multicentre Spanish study [8], carried out on 124 COPD patients with CAP, described a population with a mean forced expiratory volume in one second (FEV1) of $40 \%$ and a mean age of $67 \mathrm{yrs}$. Only $7 \%$ of the patients received chronic steroid treatment. The short-term mortality of these patients was surprisingly not very high $(8 \%)$, taking into account the severity of flow obstruction. In a more recent Spanish study, RUIZ DE OÑA et al. [9] did not find differences in mortality when stratifying patients according to risk severity classes and comparing patients with and without COPD. Specifically, in patients from class $\mathrm{V}$, mortality rates were 8 and $9 \%$,

\footnotetext{
*Servei de Pneumologia i Al.Iergia Respiratoria, Institut Clìnic del Tòrax, Hospital Clinic, IDIBAPS, Facultat de Medicina, Universitat de Barcelona, Barcelona, and "Servicio de Neumología, Hospital Universitario La Fe Valencia, Valencia, Spain.

CORRESPONDENCE: A. Torres, Servei de Pneumologia i Al.lergia Respiratoria, Institut Clìnic del Tòrax, Hospital Clínic, Villarroel, 160, 08036 Barcelona, Spain. Fax: 34932279813. E-mail: atorres@ub.edu
}

respectively. Neither study reported whether patients received steroids for the acute episode. Finally, in the score developed by FiNe et al. [2], COPD was not among the comorbidities increasing the risk of mortality.

Some considerations may help to interpret these findings. There is clear evidence that in up to $50 \%$ of stable COPD patients the lower airways are colonised by potential pulmonary pathogens [10]. This colonisation is associated with an increased local inflammatory response evidenced by increased bronchoalveolar lavage neutrophilia, tumour necrosis factor- $\alpha$ and interleukin 6. The counter-regulation of this basal inflammatory response could somehow protect these patients when the lower airways undergo an acute bacterial challenge. This could help to explain why infectious bronchitis, and not pneumonia, is much more frequent in a population with impaired bronchial defences. Logically, COPD patients would expect to have a higher incidence of CAP compared with bronchitis.

The acute administration of steroids is another confounding factor for which we do not have enough information. The acute administration of steroids decreases lung and systemic inflammatory responses [11] and, in animal models, decreases the lung bacterial burden [12]. CONFALONIERI et al. [13] performed a randomised placebo-controlled trial, comparing hydrocortisone for 7 days plus antibiotics to a standard therapy in a series of intensive care unit (ICU) patients with severe CAP. Although there were imbalances between the groups, and the investigators stopped the trial at interim analysis, the morbidity and, particularly, the mortality were much lower in the treatment group.

Few studies have reported the interactions between COPD, pneumonia and the acute administration of steroids. However, DAMBRAVA et al. [14] observed that up to $45 \%$ of hospitalised patients with CAP may receive steroids in the routine practice, and that one of the independent factors for this is the existence of COPD. It is clear that we need prospective information to separate the potential interactions between COPD, CAP and steroids.

In the present issue of the European Respiratory Journal, RESTREPO et al. [15] show some information that may help to shed light on this controversy. These authors performed a retrospective study in 744 patients with CAP and compared 215 COPD patients with 529 non-COPD patients. After adjusting for severity of disease and processes of care, COPD patients had significantly higher 30 - and 90-day mortality (1.32 
and 1.34 hazards ratio, respectively). Another recent study published in the European Respiratory Journal by RELLO et al. [16] focused on COPD patients with CAP admitted to the ICU, comparing 176 COPD patients with 252 non-COPD patients. COPD was independently associated with mortality (30 versus $21 \%$; odds ratio 1.58 ). The information provided in the two studies is important since it helps to put this debate into perspective. However, it has been fairly recognised that there are limitations that need to be considered and addressed in further studies. The study by RESTREPO et al. [15] is a retrospective analysis, while the study by RELLO et al. [16] is a retrospective analysis of prospectively collected data. These two types of studies may be subjected to bias inherent to their design.

Furthermore, neither of the two studies had prior spirometry data available to confirm the diagnosis of COPD. This is an important point for two reasons. First, some of the patients classified as COPD could, in fact, have had another chronic respiratory disease and we cannot be sure that all COPD patients were "real COPD". Secondly, the increased mortality reported could be restricted to the more severe COPD patients $(\mathrm{FEV} 1<30 \%)$ with a higher risk of difficulty for treating microorganisms, such as Pseudomonas aeruginosa.

Finally, treatment with steroids during the CAP episode is not reported in both studies. As mentioned previously, there is suspected evidence that corticosteroids may improve the outcome in severe CAP [13] and it is not known how many COPD and non-COPD patients received the adjunctive treatment. Conversely, it is well known that COPD patients receiving chronic steroid treatment have a very high mortality when they develop CAP [16]. This is well described in the article by RESTREPO et al. [15], but not in the second referring to ICU patients [13]. Both acute and chronic treatments with steroids are confounding factors when studying mortality.

Who is the third partner in this story? The answer is difficult but we suspect that the increased basal lower airway inflammatory response, presented by a large percentage of stable chronic obstructive pulmonary disease patients, plus the acute administration of steroids that these patients may receive in the routine practice, are the keys for correct interpretation. Unfortunately, we do not have the data to prove this speculation, but the ongoing prospective studies on steroids in community-acquired pneumonia will clarify the intriguing relationships between chronic obstructive pulmonary disease, community-acquired pneumonia and mortality.

\section{REFERENCES}

1 European Respiratory Society/European Lung Foundation. European Lung White Book. The First Comprehensive Survey on Respiratory Health in Europe. Loddenkemper R, Gibson GJ, Sibille Y, eds. Sheffield, UK, ERSJ, 2003.

2 Fine MJ, Auble TE, Yealy DM, et al. A prediction rule to identify low-risk patients with community-acquired pneumonia. N Engl J Med 1997; 336: 243-250.
3 Lim WS, van der Eerden MM, Laing R, et al. Defining community acquired pneumonia severity on presentation to hospital: an international derivation and validation study. Thorax 2003; 58: 377-382.

4 Menéndez R, Torres A, Zalacaín R, et al. Guidelines for the treatment of community-acquired pneumonia: an audit of adherence and outcome. Am J Respir Crit Care Med 2005; 172: 757-762.

5 Houck PM, Bratzler DW, Nsa W, Ma A, Bartlett JG. Timing of antibiotic administration and outcomes for Medicare patients hospitalized with community-acquired pneumonia. Arch Intern Med 2004; 164: 637-644.

6 Menéndez R, Torres A, Zalacaín R, et al. Risk factors of treatment failure in community-acquired pneumonia: implications for disease outcome. Thorax 2004; 59: 960-965.

7 De Celis R, Torres A, Zalacaín R, et al. Métodos de diagnóstico y tratamiento de la neumonía adquirida en la comunidad en España: Estudio NACE [Diagnostic methods and treatment of community-acquired pneumonia in Spain: NACE study]. Med Clin (Barc) 2002; 119: 321-326.

8 Torres A, Dorca J, Zalacaín R, et al. Community-acquired pneumonia in chronic obstructive pulmonary disease. Am J Respir Crit Care Med 1996; 154: 1456-1461.

9 Ruiz de Oña JM, Gómez Fernández M, Celdrán J, PuenteMaestu L. Neumonía en el paciente con enfermedad pulmonar obstructiva crónica. Niveles de gravedad y clases de riesgo [Pneumonia in the patient with chronic obstructive pulmonary disease. Levels of severity and risk classification]. Arch Bronconeumol 2003; 39: 101-105.

10 Monsó E, Ruiz J, Rosell A, et al. Bacterial infection in chronic obstructive pulmonary disease. A study of stable and exacerbated outpatients using the protected specimen brush. Am J Respir Crit Care Med 1995; 152: 1316-1320.

11 Montón C, Ewig S, Torres A, et al. Role of glucocorticoids on inflammatory response in nonimmunosuppressed patients with pneumonia: a pilot study. Eur Respir J 1999; 14: 218-220.

12 Sibila O, Luna CM, Agustí C, et al. Effect of corticoesteroids (GC) in an animal model of ventilator associated pneumonia (VAP). Am J Respir Crit Care Med 2006; 3: A21.

13 Confalonieri M, Urbino R, Potena A, et al. Hydrocortisone infusion for severe community-acquired pneumonia: a preliminary randomized study. Am J Respir Crit Care Med 2005; 171: 242-248.

14 Dambrava P, Peñarroja G, Sibila O, et al. Corticosteroid use in the treatment of community-acquired pneumonia. Am J Respir Crit Care 2006; 3: A22.

15 Restrepo MI, Mortensen EM, Pugh JA, Anzueto A. COPD is associated with increased mortality in patients with community-acquired pneumonia. Eur Respir J 2006; 28: 346-351.

16 Rello J, Rodriguez A, Torres A, et al. Implications of COPD in patients admitted to the intensive care unit by community-acquired pneumonia. Eur Respir J 2006; 27: 1210-1216. 